\title{
The Ideal Entrepreneurship Program for High Schoolers
}

\author{
Marisa Patel-O'Connor
}

\begin{abstract}
KEYWORDS: Educational Services, Entrepreneurship, Innovation, Startups.
\end{abstract}

"Sharks? Change the channel! I don't do sharks," my 12-year-old self told my older brother after I saw that he had put on some show known as Shark Tank. We ended up making a compromise in which I would have to suffer through an episode of Shark Tank before I got to watch whatever I wanted, which turned out to be a lifechanging hour for me. And before I knew it, I found myself binge-watching every episode of Shark Tank, and responding to the classic what-do-you-want-to-bewhen-you-grow-up question with "a shark."

Since I began school at the Illinois Mathematics and Science Academy(https://www.imsa.edu/) (IMSA), my aspirations of starting a business have been turning more and more into a reality. IMSA is a public, selectiveadmission, residential high school with several entrepreneurship programs. I was a student in an exceptional student-run entrepreneurship program called eleMENT (Equipping Learning Entrepreneurs (through) MENTorship), where we learned the Lean Startup Model and had the opportunity to network with entrepreneurs at 1871, a startup incubator in Chicago. Beyond this, I was a student, and now a facilitator, in SocEnt (Social Entrepreneurship), an elective class through another student-led program known as LEAD (Leadership Education And Development). This class teaches the essentials of social entrepreneurship, and equips students with the skills, people and resources to implement their own social entrepreneurship venture. Through SocEnt, my partners and I created and are in the process of implementing our business: KisumuKrafts, which serves as an online platform by which women in Kisumu, Kenya can upload their handcrafted items to sell to a wider consumer base in the US. This would not only benefit these women, but it also would show how effective the business platform is almost immediately.

\section{Too Few Opportunities Before College}

If I hadn't gone to IMSA, I would have never had such

opportunities, knowledge and a business. Unfortunately, too few high schools offer classes that nurture these entrepreneurship skills. Younger students tend to be more creative and have more "outside-of-the-box" ideas to solve problems. But these ideas often end up remaining only ideas, eventually forgotten, because the student did not have the knowledge or resources to try to implement them or even pitch them.

Students eventually get countless opportunities to pursue their interests in entrepreneurship, but not before they get to college. Rather than expanding the age group of college programs, we need to have things specifically for a younger age group. They need platforms that allow them to do something with their ideas and make connections with people in the business world. This is one of the most important aspects for getting middle/high school students involved at a younger age, as they feel more included knowing that like-minded people are around them.

\section{A Model Class}

IMSA has a program called TALENT (Total Applied Learning for ENTrepreneurs), which hosts camps for middle and early high schoolers. This presents students with simulation-based learning activities that teach them the basics of entrepreneurship. Along with camps, TALENT hosts workshops on different entrepreneurial skills every Monday night for both the IMSA and nonIMSA community. Furthermore, every year, TALENT hosts a Power Pitch competition, where students pitch their ideas in a Shark Tank-like environment, and the winners receive a grand prize of a few thousand dollars to implement their idea. And to top all of that off, everything TALENT-related (and more) takes place in IMSA's very own innovation hub packed with resources, Makerspace technology, mentors and dry-erase walls. I'd like to see other high schools adopt something similar. The events, type of space, and other details don't have to be the exact same, but the overarching idea and mission make it the ideal program for precollege students.

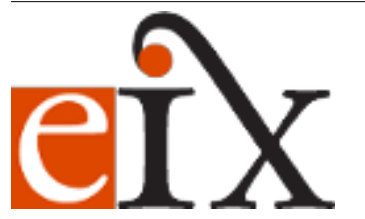

Copyright ( $) 2018$ The Authors. Entrepreneur \& Innovation Exchange is published at EIX.org. This is an open access article under the terms of the Creative Commons Attribution-NoDerivs License, which permits use and distribution in any medium, provided the original work is properly cited and no modifications or adaptations are made. View EIX.org Authorship Terms at https://eix.org/terms 
Any community can focus on strengthening the following skills, which will help high school students once they are provided with expanded entrepreneurial opportunities in college:

\section{Problem Solving}

A key part of being an entrepreneur is identifying a problem, fleshing it out and then developing an innovative solution, which is usually easier said than done. I think that one of the best ways to help students build this skill is to actually put them in a problematic situation that they must either solve or improve. With practice, this will become something that they will be doing implicitly. Whether this means that more simulations should be done during schools or an afterschool problem-solvers club should be created is up to you, but it will definitely prepare them for their future, especially if they choose to go into entrepreneurship.

\section{Developing Ideas}

In my free time, I oftentimes find myself with friends in front of a white board drawing out bubble maps or diagrams that have to do with a problem or a budding idea. Ideating is one of my favorite things to do, and it has helped me immensely with developing the skill of creating an innovative solution to a relevant problem. As a high schooler I know that I would not have even thought to do this in my free time if I hadn't been told to do it in class. All students need more opportunities that introduce them to ideation and help them use their creativity to develop ideas both in and outside school.

\section{Social and Commercial Awareness}

Along with creativity, high schools also need to promote social and commercial awareness. For students to even begin to realize that a problem exists, they need to stay aware of things going on within their community and the rest of the world. When students learn more about other businesses in the world as well as the real problems being faced, they will then begin to inquire more about entrepreneurship and/or will have more of a motive to act upon a specific problem in the future.

Doing things as simple as promoting problem solving, ideation and social awareness will help students once they get the opportunity to take action upon their ideas. With that being said, learning entrepreneurial skills at a young age not only provides them with the knowledge to develop a successful startup, but with important lifelong skills as well. Young entrepreneurs ensure sustainable growth within our world, and we need to get them ready at an early age.

Additional Search Terms: high school business courses, high school business curriculum, junior achievement, young entrepreneurs 